\title{
Fulminant type 1 diabetes with normal serum amylase: a case report
}

\author{
Yuejun $\mathrm{Ju}^{1}$, Yinghong Kong ${ }^{2}$, Mengling Zhou ${ }^{2}$, Junchen $\mathrm{Qu}^{2}$, Ting Shen ${ }^{2}$, and Shaofeng \\ Zhang $^{3}$ \\ ${ }^{1}$ Changshu NO.2 People's Hospital \\ ${ }^{2}$ Changshu No.2 People's Hospital \\ ${ }^{3}$ Changshu Medicine Examination Institute
}

March 11, 2021

\begin{abstract}
A young man was admitted to our hospital for diabetic ketoacidosis. On admission, HbA1c,GADA, serum amylase were negative. After 2 weeks of insulin therapy, serum amylase,and were GADA still negative. This report concerns a case of FT1D with normal serum.
\end{abstract}

\section{Introduction}

First reported in 2000, fulminant type 1 diabetes had the characteristics of sudden onset and rapid progression to ketoacidosis, low premier HbA1c levels, and shortage of islet-related autoantibodies ${ }^{[1]}$. FT1D, a subtype of idiopathic type 1 diabetes, has another feature of elevated serum pancreatic exocrine enzymes ${ }^{[2]}$, and contains monocytes infiltration ${ }^{[3]}$. So far, Japan has made most reports of FT1D, and FT1D occupies $3.04 \%$ of new-onset type 1 diabetes patients in China ${ }^{[4]}$. Although the cause of FT1D remains controversial, it is proved that genetic elements including human leukocyte antigen (HLA) and environmental elements including viral infections influence the occurrence of this disease ${ }^{[5]}$. Here, a case of FT1D with normal serum amylase is presented in contrast to previously reported findings.

\section{Clinical description}

Our hospital accepted an 18-year-old man on November 16, 2020. The patient showed the symptoms such as dry mouth, polydipsia, and polyuria 6 days before presentation and nausea, vomiting, and abdominal pain three days ago. After seeing a doctor in a nearby hospital, he was diagnosed with acute gastroenteritis. Despite the treatment with Pantoprazole, Metoclopramide and fluid resuscitation intravenously, his symptoms were not attenuated. On the early morning of November 15, he was sent to the emergency department of our hospital due to chest discomfort and unconsciousness. Lab test results showed significantly increased levels of fasting plasma glucose $(43.29 \mathrm{mmol} / \mathrm{L}), \mathrm{pH}$ value 7.153 and urine ketone ++ . Although the patient has no history of diabetes, his grandmother suffered from diabetes at age 60 .

He was hospitalized after being diagnosed as diabetic ketoacidosis (DKA). Upon examination, he was conscious but listless and breathed with ketone smell with the blood pressure of $118 / 76 \mathrm{mmHg}$. With the waist circumference of $75 \mathrm{~cm}$, hip circumference of $85 \mathrm{~cm}$ and body mass index (BMI) of $21.8 \mathrm{~kg} / \mathrm{m}^{2}$, he was well developed and moderately nourished. According to physical examination, no important positive signs except poor skin elasticity were found. Because his laboratory test data in Table 1 showed HbA1c of $5.7 \%$, glycosylated albumin (GA) of $19.8 \%$, serum C-peptide of less than $0.01 \mathrm{ng} / \mathrm{ml}$, serum insulin of less than 0.20 $\mu \mathrm{IU} / \mathrm{ml}$ positive serum islet cell antibody (ICA), anti-insulin antibody (IAA), GADA, tyrosine phosphatase 
antibody (IA-2A) and zinc transporter 8 autoantibody (ZnT8A), and pancreatic amylase within normal range, he was diagnosed with FT1D. After admission, he was treated with continuous intravenous infusion of small amounts of insulin and fluid replacement. After resolution of ketosis, the test of $100 \mathrm{~g}$ steamed bread meal was rechecked, and the levels of plasma glucose, C-peptide and insulin were assessed at baseline (0 minutes) and 120 minutes during the test. As shown in Table 2, the patient failed to recover islet function after inpatient treatment. During the course of the disease, abdominal CT scan indicated local edema in the liver and no abnormalities in the pancreas (Fig1). Coxsackie A/B,EV 71,EV common type,Measles virus, cytomegalovirus (CMV), adenovirus (ADV), herpes simplex virus(HSV)I/II , EB virus capsid antige ( EBVCA) were all negative except EBVCA IgG and HSVIIgG. According to HLA typing, the patient was heterozygous for HLA-DRB1*03:01-HLA-DQB1*02:01 After the resolution of DKA, he was given an insulin pump to control plasma glucose levels. After inpatient treatment, the plasma glucose was controlled stable, and the patient's insulin requirement was about 46.8 units per day.

Table 1 The laboratory results of an 18-year-old man with FT1D

\begin{tabular}{|c|c|c|}
\hline \multicolumn{2}{|l|}{ Variable } & \multirow[t]{2}{*}{ Reference range } \\
\hline Complete blood count & & \\
\hline White blood cell, $\times 10^{9}$ & 9.9 & $3.5-9.5$ \\
\hline Red blood cell, $\times 10^{12}$ & 4.47 & $4.3-5.8$ \\
\hline Hemoglobin, g/L & 142 & $130-175$ \\
\hline Hematocrit, \% & 44.4 & $40-50$ \\
\hline Platelets, $\times 10^{9} / \mathrm{L}$ & 156 & $125-350$ \\
\hline \multicolumn{3}{|l|}{ Artery blood gas analysis } \\
\hline $\mathrm{pH}$ & 7.417 & $7.35-7.45$ \\
\hline $\mathrm{pO}_{2}, \mathrm{mmHg}$ & 89.20 & $83-108$ \\
\hline $\mathrm{pCO}_{2}, \mathrm{mmHg}$ & 36.6 & $35-48$ \\
\hline Lactate, $\mathrm{mmol} / \mathrm{L}$ & 1.27 & $0.5-2.2$ \\
\hline Base excess, mmol/L & -1.0 & $-3.0-3.0$ \\
\hline Anion Gap, mmol/L & 17.1 & $8-16$ \\
\hline \multicolumn{3}{|l|}{ Urinalysis } \\
\hline $\mathrm{pH}$ & 6.5 & $5.4-8.4$ \\
\hline Protein & - & - \\
\hline Ketone bodies & +++ & - \\
\hline \multicolumn{3}{|l|}{ Biochemistry } \\
\hline AST, U/L & 28 & $9-50$ \\
\hline $\mathrm{ALT}, \mathrm{U} / \mathrm{L}$ & 22 & $15-40$ \\
\hline $\mathrm{LDH}, \mathrm{U} / \mathrm{l}$ & 205 & $120-250$ \\
\hline$\gamma$-GTP, U/L & 47 & $10-60$ \\
\hline $\mathrm{ALP}, \mathrm{U} / \mathrm{L}$ & 12 & $4-24$ \\
\hline CPK, U/L & 155 & $50-310$ \\
\hline $\mathrm{TP}, \mathrm{g} / \mathrm{L}$ & 47.8 & $65-85$ \\
\hline $\mathrm{ALB}, \mathrm{g} / \mathrm{L}$ & 16.4 & $20-40$ \\
\hline Total cholesterol, mmol/L & 2.37 & $3.0-5.75$ \\
\hline Triglyceride, $\mathrm{mmol} / \mathrm{L}$ & 0.94 & $0.4-1.7$ \\
\hline $\mathrm{Na}, \mathrm{mmol} / \mathrm{L}$ & 138.3 & $137-147$ \\
\hline $\mathrm{K}, \mathrm{mmol} / \mathrm{L}$ & 3.88 & $3.5-5.3$ \\
\hline BUN, mmol/L & 5.1 & $3.1-8.0$ \\
\hline Creatinine, umol/L & 82 & $57-97$ \\
\hline \multicolumn{3}{|l|}{ Islet-related autoantibodies } \\
\hline IAA, COI & 0.04 & $<1.0$ \\
\hline GADA, IU/mL & 4.21 & $<10$ \\
\hline GADA, IU/mL(2 week) & 3.67 & $<10$ \\
\hline
\end{tabular}




\begin{tabular}{lll}
\hline Variable & & Reference range \\
\hline IA-2A, IU/mL & 4.5 & $<10$ \\
ICA, COI & 0.27 & $<1.0$ \\
ZnT8A, IU/mL & 1.0 & $<10$ \\
Pancreatic amylase & & \\
Urine amylase, U/L & 358 & $50-875$ \\
Serum amylase, U/L & 92 & $35-135$ \\
Urine amylase, U/L $(2$ week) & 369 & $50-875$ \\
Serum amylase, U/L $(2$ week) & 95 & $35-135$ \\
Serological testing for virus & & - \\
Coxsackie A IgM & - & - \\
Coxsackie A IgG & - & - \\
Coxsackie B IgM & - & - \\
Coxsackie B IgG & - & - \\
EV 71 IgM & - & - \\
EV common type IgM & - & $<20.00$ \\
EBVCA IgM, U/mL & 12.75 & $<20.00$ \\
EBVCA IgG, U/mL & 744.00 & $0.0-0.85$ \\
CMV IgM & 0.38 & - \\
ADV IgM & - & - \\
Measles virus IgM & - & - \\
Measles virus IgG & - & - \\
HSVIIgM & - & - \\
HSVIIgG & + & - \\
HSV II IgM & - & - \\
HSV II IgG & - & HLA-DRB1*03:01-HLA-DQB1*02:01 \\
DNA typing & & \\
HLA-DRB1*03:01-HLA-DQB1*02:01 & HLA-DRB1*12:02-HLA-DQB1*03:01 & \\
HLA-DRB1*12:02-HLA-DQB1*03:01 & & \\
\hline
\end{tabular}

Table 2 Data of $100 \mathrm{~g}$ steamed bread meal test

\begin{tabular}{lll}
\hline & $0 \min$ & $120 \mathrm{~min}$ \\
\hline Blood glucose $(\mathrm{mmol} / \mathrm{L})$ & 4.82 & 24.64 \\
C-peptide $(\mathrm{ng} / \mathrm{mL})$ & $<0.01$ & $<0.01$ \\
Insulin $(\mu \mathrm{IU} / \mathrm{mL})$ & $<0.20$ & $<0.20$ \\
\hline
\end{tabular}

Fig 1 A There was local edema in the liver and normality in the pancreas during DKA. B After 2 weeks, the liver returned to normal and the pancreas was normal.

\section{Discussion}

The case of a young male patient suffering from FT1D and under normal serum amylase was described. The most common symptoms of FT1D are similar to flu-like symptoms, such as thirst and drowsiness; abdominal symptoms include nausea, vomiting, and abdominal pain ${ }^{[6]}$. FT1D has the clinical features such as the first onset of diabetic ketoacidosis, low HbA1c, near shortage of any remaining $\beta$-cells, and negative autoantibodies related to islets ${ }^{[7]}$. Our clinical outcomes in this case accorded with the diagnostic standards for FT1D. Genetic and environmental factors influence the pathogenesis of FT1D ${ }^{[8]}$. With regard to genetic factors, susceptibility to progression to FT1D is related to HLA class II genes. It is common to 
see that most East Asian populations suffer from HLA DR4 haplotype, whereas the DR3 haplotypes are related to the disease in Korea populations ${ }^{[9]}$. Our patient also showed this typical HLA type. In terms of environmental elements, viral infections, especially enterovirus infections, can cause the co-expression of interferon(IFN)-g and CXCL10 in $\beta$ cells in patients with FT1D. IFN-g can both destroy $\beta$ cells and accelerate the production of CXCL10 by the remaining $\beta$ cells. The autoimmune response is activated until the beta cells are completely destroyed. Therefore, $\beta$ cells in FT1D are destructed as the result of a vicious circle ${ }^{[10]}$. Among several patients with type 1 diabetes caused by viral infections, significantly elevated amylase can be observed, and it is considered that the mechanism is not autoimmunity, but antiviral inflammation exerts an etiopathological effect on fulminant type 1 diabetes ${ }^{[11]}$. In this case, a variety of viruses were tested without a recent viral infection. At the same time, the patient did not manifest acute pancreatitis with normal his serum amylase, and his abdominal CT did not show pancreatic inflammation. Some studies have found that the increase in serum amylase is related to the degree of DKA. In patients with severe DKA, serum amylase can account for $60 \%$, while among the patients with mild and moderate DKA, serum amylase account for only 20\%; for the patients with acute onset T1DM, severe DKA and serum amylase, the rate of increase is obvious greater than that of patients with mild to moderate severity ${ }^{[12]}$. Because our patient has a milder degree of DKA, there is no abnormal increase in serum amylase.

\section{Conclusion}

Because these findings indicate that this patient had no evidence of FT1D caused by common viral infection and not serious DKA, serum amylase was not increased.

\section{Conflict}

According to the declaration by the authors, there is no conflict of interest.

\section{References}

[1]Imagawa A, Hanafusa T, Miyagawa J, et al.. A novel subtype of type 1 diabetes mellitus characterized by a rapid onset and an absence of diabetes related antibodies. Osaka IDDM study group. N Engl J Med. 2000;342(5)301-7.

[2]Imagawa A, Hanafusa T, Uchigata Y, et al. Fulminant type 1 diabetes: a nationwide survey in Japan. Diabetes Care. 2003;26(8):2345-2352.

[3] Shibasaki S, Imagawa A, Tauriainen S, et al. Expression of toll-like receptors in the pancreas of recentonset fulminant type 1 diabetes. Endocr J. 2010;57(3):211-219.

[4]Yang D, Zhou Y, Luo S, et al. Clinical Characteristics of Fulminant Type 1 Diabetes Compared with Typical Type 1 Diabetes: One-Year Follow-Up Study from the Guangdong T1DM Translational Medicine Study. J Diabetes Res. 2020;2020:8726268.

[5]Liu L, Zeng L, Sang D, et al. Recent findings on fulminant type 1 diabetes. Diabetes Metab Res Rev. 2018;34(1):10.1002/dmrr.2928.

[6] Hanafusa T. Fulminant type 1 diabetes: 20 years of discovery and development. Diabetol Int. 2020;11(4):310-314.

[7]Luo S, Ma X, Li X, et al. Fulminant type 1 diabetes: A comprehensive review of an autoimmune condition. Diabetes Metab Res Rev. 2020;36(6):e3317.

[8]Imagawa A, Tachibana M. Fulminant type 1 diabetes: recent research progress and future prospects. Diabetol Int. 2020;11(4):336-341.

[9] Kawabata Y, Ikegami H. Genetics of fulminant type 1 diabetes. Diabetol Int. 2020;11(4):315-322.

[10] Tanaka S, Nishida Y, Aida K, et al. Enterovirus infection, CXC chemokine ligand 10 (CXCL10), and CXCR3 circuit: a mechanism of accelerated beta-cell failure in fulminant type 1 diabetes. Diabetes. $2009 ; 58(10): 2285-2291$. 
[11] Principi N, Berioli MG, Bianchini S, et al. Type 1 diabetes and viral infections: What is the relationship?. J Clin Virol. 2017;96:26-31.

[12] ZHANG Chi, ZHOU Zhi-guang, ZHANG Dong-mei, et al. Clinical and immunological characteristics in rapid-onset type 1 diabetes with hyperamylasemia. Natl Med J China.2005;85(14):967-971.

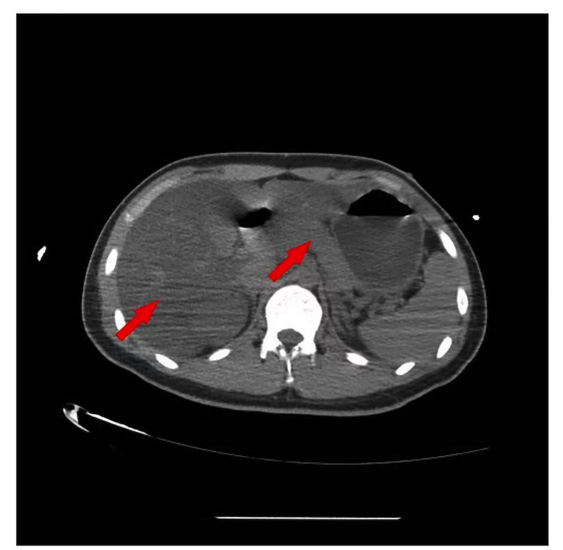

A

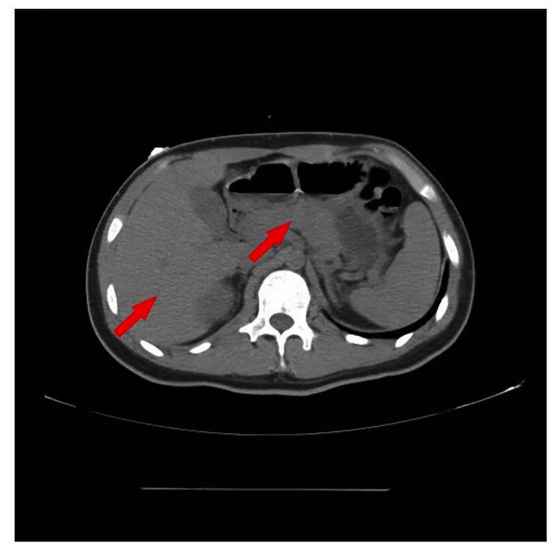

B 